\title{
BMJ Open Early-term birth and its association with universal two-child policy: a national cross-sectional study in China
}

Jie Zhang, ${ }^{1,2}$ Gareth J Williams, ${ }^{3}$ Guanghua Wang, ${ }^{4}$ Jingjing Chen, ${ }^{1,2}$
Mengyu Zhang, ${ }^{1,2}$ Wenchong Du, ${ }^{5}$ Jing Zhu, ${ }^{6}$ Jun Zhang, ${ }^{6}$ Jing Hua ${ }^{1,2}$

\section{ABSTRACT}

Objective To describe the epidemiology of early-term birth (ETB) at the national level in China, and explore the association and mediating factors between ETB and policy between universal two-child policy and ETB, so as to explain the potential reason for such a relationship and provide evidence for future ETB interventions in the era of the new birth control policy.

Design Cross-sectional study.

Participants The cross-sectional study used data from China Labour and Delivery Survey between 2015 and 2016. A total of 75132 survey data collected from 89 hospitals in 25 provinces were included in the analysis. We further explored the association between the universal two-child policy and ETB.

Results The weighted incidence of ETB was 30.1 per 100 all births $(95 \% \mathrm{Cl} 30.06 \%$ to $30.14 \%)$ or 29.88 per 100 live births (95\% Cl 29.97\% to 30.05\%) between 2015 and 2016 in China. There was an association between the universal two-child policy and ETB (relative risk, RR 1.19, $95 \% \mathrm{Cl} 1.15$ to 1.23 ), which was not mediated by maternal age (RR $1.17,95 \% \mathrm{Cl} 1.13$ to 1.22 ), previous uterine scars (RR $1.18,95 \% \mathrm{Cl} 1.14$ to 1.22 ), parity (RR 1.19, $95 \% \mathrm{Cl} 1.15$ to 1.24 ) and other measured conditions (each $p<0.05)$. Stratified analysis showed that the association between universal two-child policy and ETB were the strongest in multiparous young women or women without previous uterine scars (each $p<0.05$ ), and disappeared in all women of advanced maternal age (each $p>0.05$ ). Conclusion The incidence of ETB was high in China when compared with most of reported countries, and there might be a link between two-child policy and ETB. Obstetric practice such as selective induced labour and caesarean section should be revised with ETB risks in mind, when ETB is more likely to happen under the universal twochild policy. Preventing ETB should not be neglected in multiparous young women or those without previous uterine scars under the new policy.

(C) Author(s) (or their employer(s)) 2021. Re-use permitted under CC BY-NC. No commercial re-use. See rights and permissions. Published by BMJ.

For numbered affiliations see end of article.

Correspondence to

Professor Jing Hua;

Jinghua@tongji.edu.cn

\section{INTRODUCTION}

Early-term birth (ETB) is defined as infants delivered at a gestation age between $37^{0 / 7}$ and $38^{6 / 7}$ weeks $^{1}$, which accounts for $15 \%-31 \%$ of all deliveries, and far exceeds the number of preterm births. ${ }^{2}$ Preterm infants are often at a higher risk of morbidity and mortality compared with full-term infants, ${ }^{3}$ and recent

\section{Strengths and limitations of this study}

The strength of this study is first report the rates of early-term birth (ETB) before and after the implementation of the universal two-child policy.

- The most important population for further intervention of ETB under the new policy was presented using a stratified analysis.

- The evidence provided by our study was reliable because it based a large sample in China at national level.

- Missing and excluded information appeared not to substantially affect the results in our study using a sensitivity analysis.

- We do not have a complete profile of mediating factors such as smoking, physical activity, eating habits and economic status.

reports also suggested that ETB is associated with significantly higher health risks, including higher neonatal, postnatal, and infant mortality and morbidity rates when compared with full-term infants (>38 gestational weeks $)^{4}$; ETB can also have a longterm impact on children's cognition and behaviour. ${ }^{5}$ However, the epidemiology of ETB is scarce in China despite a large number of studies on preterm birth. ${ }^{6-12}$

Since October 2015, China's one-child policy has been replaced with a universal twochild policy (which allows a family to have two children). However, the relationship between universal two-child policy and newborn outcomes births is still unclear. Studies have reported that the change of the birth control policy might result in nationwide changes to a range of health outcomes, such as a more equal sex ratio, reduced neonatal mortality, ${ }^{13}$ and increased risk of birth defects. ${ }^{14}$ However, the new two-child policy might also be associated with outcomes related to birth term.

One of the potential consequences which is associated with the two-child policy might be an increased rate of ETB, which can be influenced by a range of factors, for example, 
pregnancies in mothers of advanced maternal age ( $\geq 34$ years) have increased since the implementation of the universal two-child policy, ${ }^{14-17}$ and there is an increased risk of pregnancy complications in women of advanced maternal age. ${ }^{14} 18$ Complications during pregnancy, such as placental ischaemia and diabetes mellitus, increase the risk of ETB. ${ }^{19}$ Additionally, a higher primary caesarean section (C-Section) rate in China means that a more pregnant women who have had a previous birth have uterine scars. ${ }^{20}{ }^{21}$ To avoid rupturing the uterus, early elective birth is more likely to be a decision for women with previous scars ${ }^{322} 23$; the uterus scar site is more susceptible to tearing and rupture when subjected to pressure during labour. Therefore, with those possible influencing factors, a higher incidence of ETB might be observed after the implementation of the universal two-child policy.

Furthermore, studies showed that the relationship of universal two-child policy with obstetric issues can vary across different maternal characteristics. ${ }^{13} 1624$ For example, it has been reported that the associations between the two-child policy and sex ratios differed by maternal age, parity,and history of C-section. ${ }^{13}$ It has also been found that the association of two-child policy with caesarean birth rate varies between nulliparous and multiparous women. ${ }^{24}$ Moreover, the risk of childbearing policy on incidence of birth defects has been found to be higher in women aged 30-34 years old when compared with their younger counterparts. ${ }^{14}$

In the current study, we aimed to describe the epidemiology of ETB in China by using a nationwide dataset from the China Labour and Delivery Survey (CLDS). Additionally, we analysed the association between the incidence of ETB and the two-child policy in terms of different maternal characteristics (such as maternal age, previous uterine scars and parity). We also explored the factors that might mediate the association between ETB and policy so as to explain such a relationship and offer evidence for future ETB interventions in the era of the new birth control policy.

\section{METHODS \\ Sample}

Data for this national cross-sectional study were acquired from the dataset of the CLDS, which is a populationbased multicentre study that describes the incidence, risk factors and possible underlying causes of ETB in China. We extracted the data between 2015 and 2016 because the one-child policy has been replaced with a two-child policy since October 2015. Participation was solicited through a national obstetric conference hosted by Shanghai First Maternity and Infant Hospital, Tongji University School of Medicine.

We used the same methodology as the WHO Global Survey of Maternal and Perinatal Health and the WHO Multi-Country Survey of Maternal and Newborn Health to perform data collection. ${ }^{25} 26$ The hospitals that expressed an interest in taking part in the research were asked to provide basic information about the hospitals, and only those with 1000 or more deliveries per year (having sufficient obstetrical faculty) were eligible for being including in this study. To ensure that there was a representative sample of ETB, we selected the hospitals with 1000 or more deliveries per year which covered most Chinese provinces (25 out of 34). With reference with the WHO methodology, ${ }^{25}{ }^{26}$ for hospitals with an annual rate of more than 6000 deliveries per year, we divided the 1 -year period into 13 time-sections and randomly selected 6 weeks of records, whereas for hospitals with an annual delivery rate of less than 6000 per year, ten weeks were randomly selected within a 1-year period, divided into five time sections. Within each selected week, all births delivered at 24 or more completed weeks of gestation or weighing 500 grams or more at birth were eligible. Medical records were retrieved and reviewed, and information was extracted by trained research nurses. The study design, organisation and implementation have also been reported in another study. ${ }^{27}$ Using the WHO methodology allows for comparability between these results and the studies of other countries.

A data coordination centre was established to take charge of establishing, managing and maintaining the database and website, coordination among hospitals and investigators' training. This study did not involve individual informed consent because the centre collected anonymous clinical information only. All information was kept confidential, and only the cooperators of our research could access the database when their application was approved by the data coordination centre. Additionally, the centre was also responsible for data logic checking, assessing of study protocol and other quality control measures of the data.

A total of 75132 birth records were initially included in the analysis from 89 hospitals in China between 1 March 2015 and 31 December 2016. Among these birth records, a total of 73567 live birth were included for calculating the incidence of ETB at a national level. In order to further analyse the association of ETB with the implementation of the universal two-child policy, we chose the women who were pregnant after October 2015 (the universal two-child policy was announced) and gave birth to children after July 2016 (the effective period: 9 months after the announcement of the universal twochild policy) according to previous studies. ${ }^{15}$ The women who gave birth to a child before October 2015 (before the announcement of the universal two-child policy) were included as controls. A total of 28966 live singleton fullterm birth were included in the final analysis (figure 1).

\section{Patient and public involvement}

Patients or the public were not involved in the design, conduct, reporting or dissemination plans of our research.

\section{Exposure, outcomes and other covariates}

ETB, which was defined as newborn delivery occurring between $37^{0 / 7}$ to $38^{6 / 7}$ weeks of gestation, was the main 


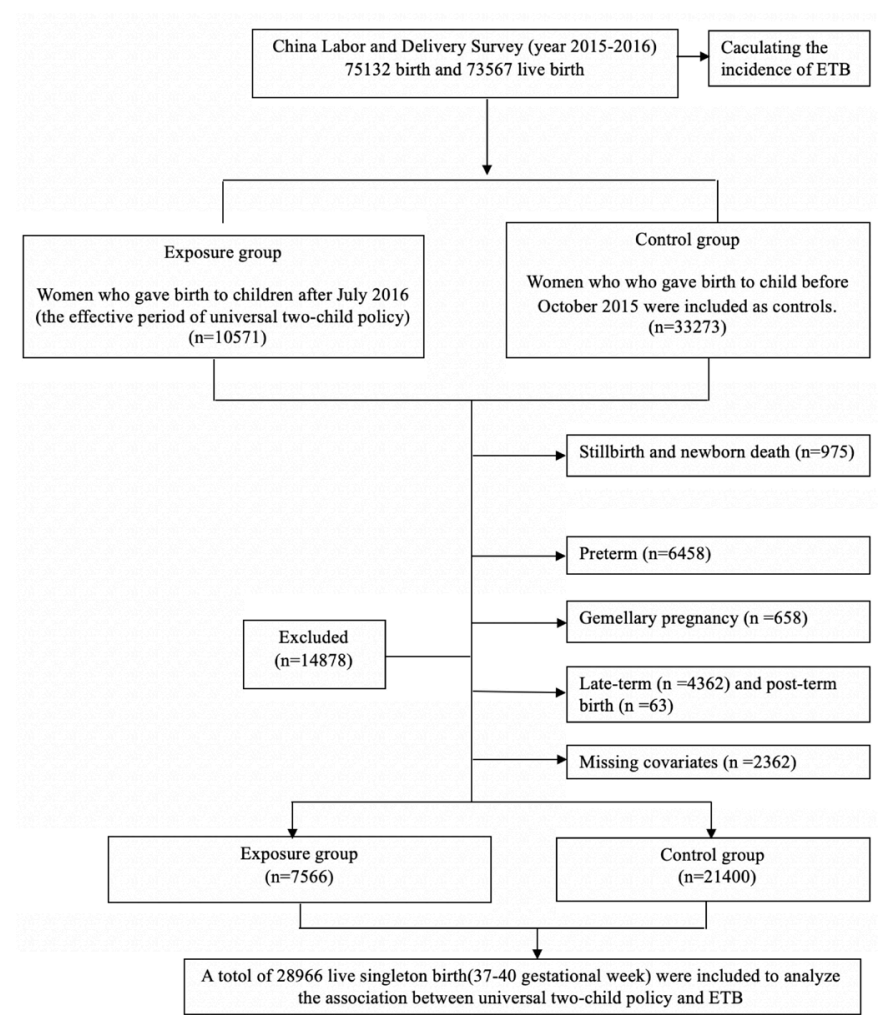

Figure 1 Flow chart of study population. Flow chat of the study inclusion and exclusion criteria for review of total participant samples and how the final number of the cohort was established. ETB, early-term birth.

outcome of our study. Gestational age was determined by obstetrical providers with the use of standard criteria that took into consideration the clinical history and the results of the earliest ultrasound examination. ${ }^{28}{ }^{29}$ If the gestational age as calculated from an early ultrasound is contradictory to the one calculated directly from the last menstrual period, it is the age calculated from the early ultrasound that is used for the rest of the pregnancy. ${ }^{30} 31$

We included the maternal age, previous uterine scar, parity and precursors as mediating factors (which refer to the factors that could mediate the relationship between the independent and dependent variables so as to explain the reason for such a relationship to exist). Precursors for delivery were defined using the following four categories: spontaneous labour, premature rupture of membranes (PROM), indicated and elective induction or C-Section, which has also been used to assess the reasons for late preterm birth according to previous study. ${ }^{32}$ Spontaneous labour was defined as women with the spontaneous start of labour and with or without complications or rupture of membranes during pregnancy. PROM was defined where a woman presented with PROM and underwent induction labour or prelabour C-Section, but exclusive of spontaneous labour. Indicated deliveries included women without spontaneous labour or PROM who underwent induction labour or prelabour C-Section for maternal, fetal or obstetric complications. ${ }^{33} 34$ We also categorised as indicated any delivery where induction of labour or indication for prelabour C-Section was not recorded, but the pregnancy had other complications such as hyperthyroidism or hypothyroidism, and hypertensive disease or gestational diabetes. Elective induction or C-Section included elective inductions or C-Section as identified by the site with no other obstetrical, fetal or maternal conditions, and there was no reason for induction or C-Section provided, or no other obstetrical, fetal or maternal conditions. ${ }^{35} 36$

Additionally, it has been reported that the prepregnancy body mass index (BMI) is related with gestational ages. ${ }^{37}{ }^{38}$ We included it as a potential confounder when considering the association between two-child policy and ETB. We used maternal prepregnancy weight and height to calculate BMI, which was grouped into three categories: underweight $\left(<18.5 \mathrm{~kg} / \mathrm{m}^{2}\right)$, normal weight $\left(18.5-24.9 \mathrm{~kg} / \mathrm{m}^{2}\right)$ and overweight or obesity $(\geq 25 \mathrm{~kg} /$ $\mathrm{m}^{2}$ ) according to the WHO BMI classification. ${ }^{39}$ Maternal height was presented in quartiles (Q1: $100-160 \mathrm{~cm}, \mathrm{Q} 2$ : $161-165 \mathrm{~cm}, \mathrm{Q} 3: 166-168 \mathrm{~cm}, \mathrm{Q} 4: 169-190 \mathrm{~cm}$ ).

\section{Statistical analysis}

To better represent the epidemiology of ETB in China, we calculated weight for each birth in the survey by using the number of deliveries in each province from the 2016 China Statistical Yearbook, compiled by the National Bureau of Statistics of China (http://www.stats.gov.cn/ tjsj/ndsj/2016/indexch.htm). We calculated a 95\% CI of the incidence of Early term with the Normal approximation. We analysed the difference between the precursors of delivery in ETB before and after the implementation of the universal two-child policy using the partitions of the $\chi^{2}$ method.

We presented the maternal and newborn's characteristics in the study population by the status of birth control policy and by the different gestational ages (online supplemental file 1). These characteristics were considered as potential confounders (covariates) when we analysed the association between two-child policy and ETB. A multivariable regression model was used to analyse the associations between universal two-child policy and ETB when adjusting for or not adjusting for the maternal and newborn characteristics (as confounders).

We carried out a stratified analysis according to maternal age, parity, and previous uterine scar to explore potential disparities in the association of ETB with a universal twochild policy. To further clarify the association, we carried out analyses to detect the joint effect of each age group by subgroup of parity or previous uterine scar. We added the interaction term (maternal age xparity or maternal age $\times$ uterine scars) to the model. When an interaction is confirmed (with statistical significance), strata-specific estimates are reported.

Additionally, we did a series of sensitivity analyses by including all subjects and excluding women who had gestational week $<37$, with Gemellary pregnancy and stillbirth or newborn death, late-term and post-term birth, 
missing of covariates on the association between two-child policy and ETB.

Relative risk (RR) and 95\% CI was estimated using a multilevel modified Poisson regression approach. ${ }^{40}$ For controlling the unmeasured confounding factors from different hospitals, we used a multilevel model (considering the hospital as the cluster) in our study. The application of Poisson regression on multinominal data has been shown to overestimate the RR. ${ }^{4041}$ We rectified this using a robust error variance procedure known as sandwich estimation, in our modified Poisson regression ${ }^{40}$ using PROC GENMOD in SAS V.9.4 software. A p value of $<0.05$ was considered statistically significant.

\section{RESULTS}

Among all births $(\mathrm{n}=75132)$ and live births $(\mathrm{n}=73567)$, the unweighted incidence of ETB was $31.88 \%$ per 100 all births (95\% CI $31.55 \%$ to $32.21 \%$ ) and $31.72 \%$ per 100 live births (95\% CI $31.38 \%$ to $32.06 \%$ ), respectively. After weighting adjustment, the weighted incidence of ETB was $30.1 \%$ per 100 all births (95\% CI $30.06 \%$ to $30.14 \%$ ) and $29.88 \%$ per 100 live births (95\% CI $29.97 \%$ to $30.05 \%$ ) in China, respectively. Of 75132 birth, $41.75 \%$ of all weighted births occurred with spontaneous labour, followed by indicated $(41.32 \%)$, PROM $(13.83 \%)$ and elective induction or C-Section (3.10\%). Of 73567 live births, $41.75 \%$ occurred with spontaneous labour, followed by indicated (41.32\%), PROM $(14.09 \%)$ and elective induction or C-Section $(2.45 \%)$. There were substantial variations of ETB according to maternal age, previous uterine scars and parity (table 1).
Of 28966 women, 7566 women were included in the exposure group (after the implementation of two-child policy) and 21400 women (before the implementation of two-child policy) were included in the control group. There was a statistically significant difference in most of the maternal and newborn characteristics between the exposure and control groups, and between ETB and completely full-term birth $(p<0.05$ online supplemental eTable 1), so these were included as mediating or confounding factor in our study. In table 2, the results showed there were associations between universal twochild policy and ETB when not adjusting for (RR 1.19, $95 \%$ CI 1.15 to $1.23, \mathrm{p}<0.001$ ) or adjusting for maternal age (RR $1.17,95 \%$ CI 1.13 to $1.22, \mathrm{p}<0.001$ ), previous uterine scars (RR $1.18,95 \%$ CI 1.14 to $1.22, p<0.001$ ), parity (RR $1.19,95 \%$ CI 1.15 to $1.24, \mathrm{p}<0.001$ ) and all above three conditions (RR $1.17,95 \%$ CI 1.13 to $1.21, \mathrm{p}<0.001$ ). The statistical significance remained when precursors for delivery (RR $1.18,95 \%$ CI 1.14 to $1.23, \mathrm{p}<0.001$ ) and all measured characteristics (RR $1.19,95 \%$ CI 1.14 to 1.22 , $\mathrm{p}<0.001)$ were added to the adjustment.

In the stratified analysis, we found that the association of universal two-child policy with ETB varied by different ages, previous uterine scars and parity (table 3 ). The association between universal two-child policy and ETB differed significantly by maternal age and uterine scars $\left(p_{\text {interaction }}=0.0026\right)$. We analysed the association when stratified by age xprevious uterine scars (figure 2). The association of universal two-child policy with ETB was statistically significant in women younger than 30 years of age with previous uterine scars (adjusted $R R=1.19$,

Table 1 Incidence of early-term birth by maternal age, previous uterine scar, parity and precursors for delivery ( $\mathrm{n}=73567$ )

\begin{tabular}{|c|c|c|c|c|c|}
\hline \multirow[b]{2}{*}{ Characteristics } & \multirow[b]{2}{*}{ Total } & \multicolumn{2}{|l|}{ Unweighted } & \multicolumn{2}{|l|}{ Weighted } \\
\hline & & Incidence (\%) & $95 \% \mathrm{Cl}$ & Incidence (\%) & $95 \% \mathrm{Cl}$ \\
\hline \multicolumn{6}{|l|}{ Maternal age } \\
\hline $30-34$ & 19141 & 31.87 & 31.53 to 32.21 & 30.67 & 30.34 to 31.00 \\
\hline$\geq 35$ & 8444 & 35.14 & 34.80 to 35.48 & 34.38 & 34.04 to 34.72 \\
\hline \multicolumn{6}{|l|}{ Previous uterine scars } \\
\hline Yes & 10681 & 42.84 & 42.48 to 43.20 & 40.25 & 39.90 to 40.60 \\
\hline No & 62886 & 26.07 & 25.75 to 26.39 & 24.81 & 24.50 to 25.12 \\
\hline \multicolumn{6}{|l|}{ Parity } \\
\hline Nulliparous & 41302 & 24.96 & 24.65 to 25.27 & 23.27 & 22.96 to 23.58 \\
\hline PROM & 8616 & 33.57 & 33.23 to 33.91 & 34.58 & 34.24 to 34.92 \\
\hline Indicated* & 28815 & 31.67 & 31.33 to 32.01 & 29.79 & 29.46 to 30.12 \\
\hline Elective induction or C-Section & 2178 & 23.92 & 23.61 to 24.23 & 21.53 & 21.23 to 21.83 \\
\hline
\end{tabular}

*'Indicated' precursors refer to women with maternal, fetal or obstetric complications.

C-Section, caesarean section; PROM, premature rupture of membranes. 
Table 2 Association between universal two-child policy and early-term birth when adjusting for maternal and newborn's characteristics $(n=28966)$

\begin{tabular}{|c|c|c|}
\hline Adjusting variables & $\begin{array}{l}\text { Adjusted RR } \\
(95 \% \mathrm{Cl})\end{array}$ & $P$ value \\
\hline Crude* $^{*}$ & 1.19 (1.15 to 1.23$)$ & $<0.0001$ \\
\hline Maternal age & 1.17 (1.13 to 1.22$)$ & $<0.0001$ \\
\hline Previous uterine scars & 1.18 (1.14 to 1.22$)$ & $<0.0001$ \\
\hline Parity & $1.19(1.15$ to 1.24$)$ & $<0.0001$ \\
\hline $\begin{array}{l}\text { Maternal age +previous } \\
\text { uterine scars+parity }\end{array}$ & $1.17(1.13$ to 1.21$)$ & $<0.0001$ \\
\hline $\begin{array}{l}\text { Maternal age +previous uterine } \\
\text { scars+parity+precursors for } \\
\text { delivery }\end{array}$ & $1.18(1.14$ to 1.23$)$ & $<0.0001$ \\
\hline $\begin{array}{l}\text { Maternal age +previous uterine } \\
\text { scars+parity+precursors for } \\
\text { delivery +the other maternal } \\
\text { and newborn characteristicst }\end{array}$ & 1.18 (1.14 to 1.22$)$ & $<0.0001$ \\
\hline
\end{tabular}

${ }^{*}$ Not adjusted for any variables.

†The other maternal and newborn characteristics were shown in online supplemental eTable 1.

$\mathrm{RR}$, relative risk.

$\mathrm{p}<0.05)$ and without previous uterine scars (adjusted $\mathrm{RR}=1.25, \mathrm{p}<0.05)$. The association remained among those aged from 30 to 34 without previous uterine scars (adjusted $\mathrm{RR}=1.19, \mathrm{p}<0.05$ ), however, disappeared in those with previous uterine scars $(\mathrm{p}>0.05)$. The association disappeared for all women aged more than 34 years with and without previous uterine scars (each $\mathrm{p}>0.05$ ). The crude RR and $95 \% \mathrm{CI}$ of RR were shown in figure 2.

We found the associations between universal two-child policy and ETB differed significantly by maternal age and parity $\left(p_{\text {interaction }}=0.0155\right)$. Therefore, we ran further analyses for strata-specific estimates by age xparity (figure 1 ). The universal two-child policy was positively associated with ETB among nulliparous and multiparous women younger than 30 years old (adjusted RR were 1.23 and 1.31 , respectively, $\mathrm{p}<0.05$ ), nulliparous and multiparous women aged 30-40 years (adjusted RR were 1.14 and 1.16 , respectively, each $\mathrm{p}<0.05$ ), but the association disappeared among nulliparous and multiparous women older than 34 years when adjusting for maternal and newborn characteristics (each $p>0.05$ ). The crude RR and 95\% CI of RR were shown in figure 3 .

Sensitivity analyses, in which we did not exclude any variables or only excluded preterm births, gemellary pregnancy, stillbirth and neonatal death, and missing covariates yielded similar results when compared with our main analysis (each $p>0.05$ ). The finding changed with marginal significance, in contrast to our main analysis, when we excluded late-term and post-term birth from the overall subjects ( $p=0.05$, online supplemental eFigure 1 ).

\section{DISCUSSION}

To our knowledge, the current study is the first to describe the incidence of ETB in China at a national level. We observed an incidence of about $30 \%$ of ETB between 2015 and 2016 in China and an increased risk of ETB after the announcement of the universal two-child policy. However, the association between ETB and the universal two-child policy was not mediated by maternal age, previous uterine scars, parity and other measured characteristics. Furthermore, the stratified analysis showed that the effects of the universal two-child policy on ETB was strongest in multiparous young women or those without previous uterine scars, and disappeared in all women

Table 3 Association between universal two-child policy and early-term birth stratified by maternal age, previous uterine scars and parity $(n=28966)$

\begin{tabular}{|c|c|c|c|c|}
\hline Adjusted variables & Crude $\mathrm{RR}^{\star}(95 \% \mathrm{Cl})$ & $P$ value & Adjusted RR† (95\% Cl) & $P$ value \\
\hline \multicolumn{5}{|l|}{ Maternal age } \\
\hline$<30$ & $1.22(1.16$ to 1.28$)$ & $<0.0001$ & 1.24 (1.18 to 1.30$)$ & $<0.0001$ \\
\hline $30-34$ & 1.15 (1.08 to 1.22$)$ & $<0.0001$ & 1.14 (1.07 to 1.22$)$ & $<0.0001$ \\
\hline$\geq 35$ & 1.06 (0.97 to 1.15$)$ & 0.1816 & 1.05 (0.97 to 1.15$)$ & 0.2241 \\
\hline \multicolumn{5}{|l|}{ Previous uterine scars } \\
\hline No & 1.20 (1.16 to 1.25$)$ & $<0.0001$ & 1.21 (1.16 to 1.26$)$ & $<0.0001$ \\
\hline Yes & $1.08(1.02$ to 1.15$)$ & 0.0104 & $1.08(1.01$ to 1.15$)$ & 0.0263 \\
\hline \multicolumn{5}{|l|}{ Parity } \\
\hline Nulliparous & 1.18 (1.12 to 1.24$)$ & $<0.0001$ & 1.19 (1.13 to 1.26$)$ & $<0.0001$ \\
\hline Multiparous & $1.20(1.14$ to 1.25$)$ & $<0.0001$ & 1.17 (1.12 to 1.23$)$ & $<0.0001$ \\
\hline
\end{tabular}

${ }^{*}$ Not adjusted for any variables.

†Adjusted for maternal sociodemographic status, maternal health conditions and newborn's characteristic.

$\ddagger$ Adjusted for maternal sociodemographic status.

$\S$ Adjusted for maternal health conditions.

IAdjusted for newborn's characteristics.

$\mathrm{RR}$, relative risk. 
A Without previous uterine scars(unadiusted)

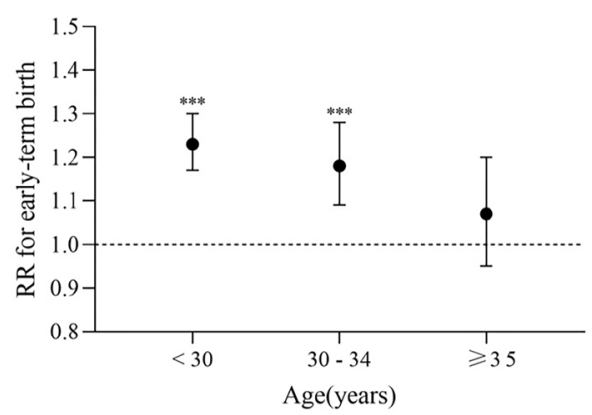

C Previous uterine scars(unadjusted)

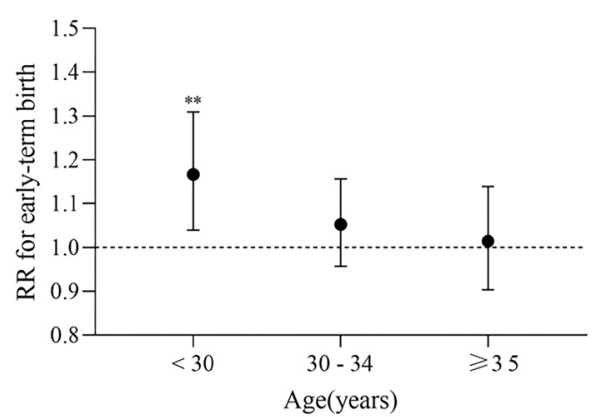

B Without previous uterine scars(adjusted)

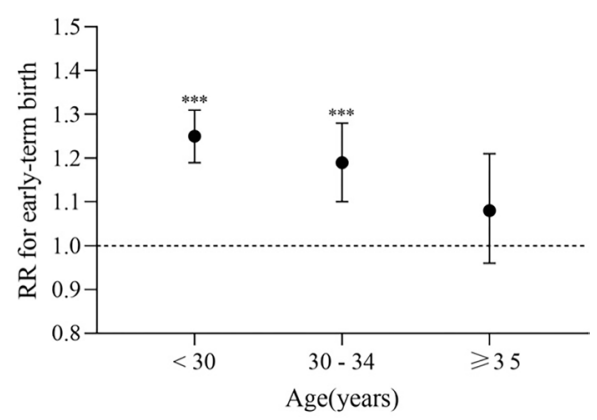

D Previous uterine scars(adjusted)

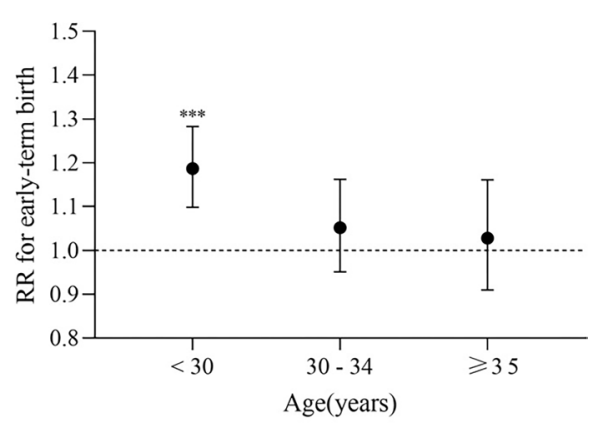

Figure 2 Association between universal two-child policy and early-term birth (ETB) in women without previous uterine scars when not adjusting other variables $(A)$, without previous uterine scars when adjusting other variables $(B)$, with previous uterine scars when not adjusting other variables (C), with previous uterine scars when adjusting other variables (D), by maternal age group $(\mathrm{n}=28966)$. The association between universal two-child policy and ETB when stratified by age $\times$ previous uterine scars. $\mathrm{RR}$, relative risk. ${ }^{*} p<0.05,{ }^{* *} p<0.01$

of advanced maternal age (irrespective of parity and previous uterine scars).

The incidence of ETB in different countries is varied. For example, a population study reported that the average incidence of ETB was $25.3 \%$ among six highincome countries. ${ }^{42}$ In that study, a lower incidence was reported in Denmark, Finland, Norway, and Sweden (all below 20\%), and a higher incidence was reported in the USA and Canada (higher than 20\%). In other countries, the reported incidence of ETB is fairly consistent. For example, a multicentred study from 44 hospitals in Portugal reported an incidence of ETB of $27 \% .^{43}$ Another national study in Brazil reported an incidence of ETB of $29.8 \%$ in singleton deliveries. ${ }^{44}$ The incidence of ETB in China of about $30 \%$ between 2015 and 2016 can be therefore considered as similar to Portugal and Brazil, but higher than most of reported countries. The variations of ETB across different maternal age, parity and women with or without previous uterine scars in China were consistent with previous studies. ${ }^{19} 45-49$

Of the reported ETB cases in the current study, about $3 \%$ were due to having an elective delivery. It has been reported that the ETB rates in the USA decreased from $33.0 \%$ in 2006 to $21.1 \%$ in 2014 among births with clinician-initiated obstetric intervention, and from $29.7 \%$ in 2006 to $27.1 \%$ in 2014 among births without clinicianinitiated obstetric intervention. ${ }^{42}$ These studies ${ }^{42} 5051$ found that reductions in elective obstetric intervention at ETB may reflect the success of interdisciplinary healthcare teams that focus on decreasing elective births before 39 weeks. ${ }^{52-54}$ Therefore, our result suggests that the ETB rate in China may decrease if obstetric intervention reduces the number of unnecessary elective deliveries.

Owing to the timing of the initiation of the universal two-child policy across the research period, we explored ETB rate changes after the implementation of the universal two-child policy, so as to provide evidence for future ETB interventions in the era of the new policy. Our study reported that the incidence of ETB increased after the implementation of the universal two-child policy, however, the association stayed statistically significant after mediated by maternal age, previous uterine scar, parity and the other maternal and newborn factors in etable1. The results suggest that the two-child policy might bring other risk factors that were not included in our study. A recent study suggested that under the newly relaxed universal two-child policy, women may experience higher risk of mental health difficulties during their second pregnancy, ${ }^{55}$ and poorer mental health may lead to a higher chance of ETB. Further research is necessary to explore the association between ETB and maternal and newborn outcomes, to reveal more details of the underlying mechanisms of ETB, and inform new interventions for pregnant women.

We found that there was an association between China's two-child policy and ETB which differed across 


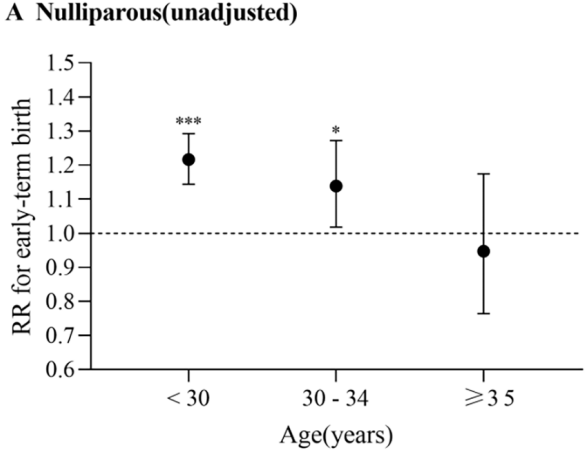

C Multiparous(unadjusted)

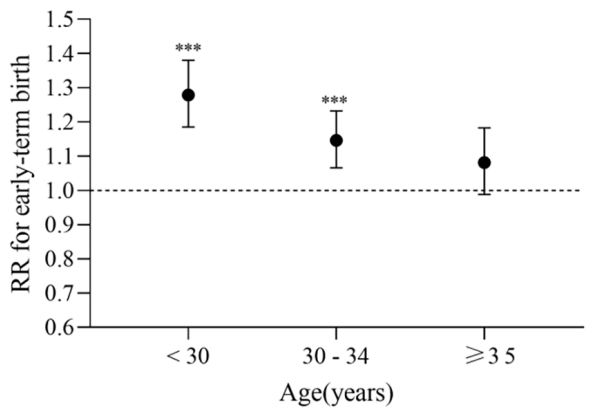

B Nulliparous(adjusted)

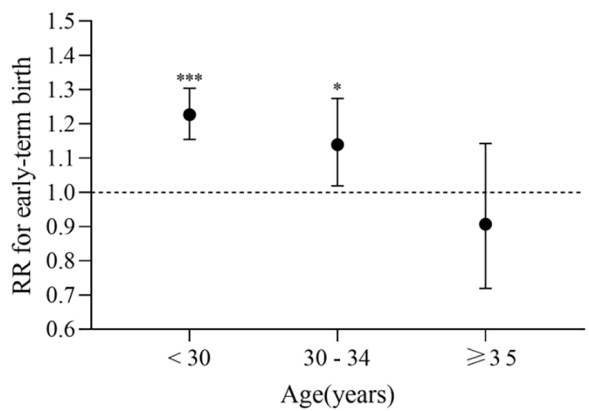

D Multiparous(adjusted)

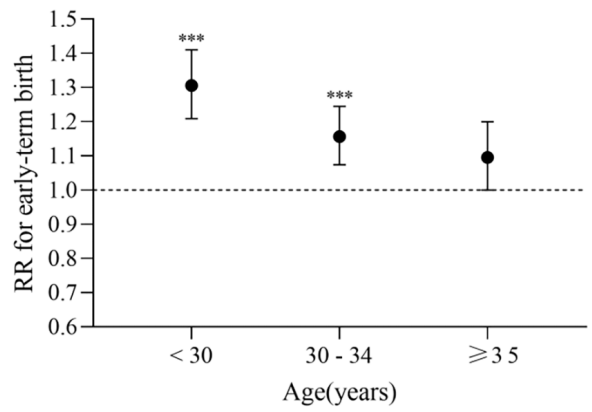

Figure 3 Association between universal two-child policy and early-term birth (ETB) in nulliparous women when not adjusting other variables (A), in nulliparous women when adjusting other variables (B), in multiparous women when not adjusting other variables $(C)$, in multiparous women when adjusting other variables $(D)$, by maternal age group $(n=28966)$. The diagram analysed the association between universal two-child policy and ETB when stratified by age $\times$ pairty. RR, relative risk. ${ }^{*} p<0.05,{ }^{* *} p<0.01$

subjects with different maternal characteristics, especially, maternal age. One likely explanation for why the association was not present in women of advanced maternal age (but remained in women with younger age), is a 'ceiling effect'. Women of advanced maternal age are at risk of higher rates of ETB as they are more vulnerable to maternal complications and adverse birth outcomes. Obstetric complications such as placental abruption, ${ }^{56}$ malpresentation and postpartum haemorrhage ${ }^{45465758}$ are higher in women of advanced maternal age. Unexplained stillbirths increase with advancing maternal age and with increasing gestational age in both nulliparous and multiparous women. Therefore, the induction of labour or prelabour C-Section in women of advanced maternal age is widely practiced as an intervention perceived to reduce the risk of adverse perinatal outcomes. ${ }^{46}$ Those factors may reduce the difference in ETB rates in women of advanced maternal age before and after the implementation of the universal two-child policy.

We also found that the effect of the universal two-child policy on ETB was the strongest in young women without previous uterine scars, or who are multiparous. It has been reported that early elective birth before 39 weeks is more likely to occur in women with previous scars when obstetricians do not appreciate the risk of morbidity of infants before 39 weeks and prefer to maintain autonomy in determining the timing of delivery. ${ }^{3}$ Therefore, the probability of early elective birth in women with previous uterine scars may moderate the difference in ETB before and after the implementation of the universal two-child policy. Additionally, the effects of the policy on ETB increased more significantly in multiparous young women than their nulliparous counterparts. One possible explanation is that first-time mothers are more likely to have a spontaneous vaginal delivery, instead of an elective birth week, so that they are able to reduce the risk of potential health complications that might arise from a second pregnancy ${ }^{59}$ thus reducing the difference in ETB rate in nulliparous women before and after the implementation of the universal two-child policy.

\section{Strengths and limitations}

With the large sample in our study, we first reported the incidence of ETB at a national level and found an association between universal two-child policy and ETB. However, there were several limitations to our study. First, we do not have a complete profile of factors that may influence the association between universal two-child policy and ETB. For example, we have comparatively little information on maternal behaviour, such as smoking, physical activity and eating habits, and were unable to measure the influence of psychological disorders (eg, depression, anxiety) on ETB in this study. Furthermore, future studies including sociological variables such as maternal economy, marital status, income, education and occupation could help further explain these findings. 
We will explore these potential factors in our subsequent study. Second, we excluded the stillbirth (or newborn death), preterm birth, gemellary pregnancy, late-term and post-term birth, missing covariates in our study, and thus our findings may not be generalised to these populations. However, in the sensitivity analysis of our study, it did not appear to substantially affect the results.

\section{CONCLUSION}

The incidence of ETB was high in China when compared with most of reported countries and practice patterns should be adjusted to respond to ETB, when ETB was found to be more likely to happen under the universal two-child policy. The underlying mechanisms have yet to be elucidated; the mediating effects of maternal age, parity and previous uterine scars on the association between universal two-child policy and ETB need to be explored further, in a more diverse dataset, with a more comprehensive range of information for potential confounding factors.

\section{Author affiliations}

${ }^{1}$ Department of Women and Children's Health Care, School of Medicine,Tongji University, Shanghai, China

${ }^{2}$ Shanghai Key Laboratory of Maternal Fetal Medicine, Shanghai First Maternity and Infant Hospital, School of Medicine,Tongji University, Shanghai, China ${ }^{3}$ School of Social Sciences, Nottingham Trent University, Nottingham, UK ${ }^{4}$ Department of Obstetrics and Gynecology, Tongren Hospital, Shanghai Jiaotong University School of Medicine, Shanghai, China

${ }^{5}$ Department of Psychology, Nottingham Trent University, Nottingham, UK ${ }^{6}$ Ministry of Education-Shanghai Key Laboratory of Children's Environmental Health, Xinhua Hospital, Shanghai Jiao Tong University School of Medicine, Shanghai, China

Contributors $\mathrm{JH}$ conceptualized and designed the study, reviewed and critically revised the manuscript. JZ, GW and WD drafted the initial manuscript. JH, JZ, JC and WD conducted the data analysis. JC, JZ, JZ and MZ established the cohort and provided intellectual inputs to the manuscript. GJW were responsible for and supervising data collection and critical revision of the manuscript for important intellectual content. All authors reviewed and approved the final version of the manuscript.

Funding This study was partly supported by National Natural Science Foundation of China (81673179), the Science and Technology Commission of Shanghai Municipality (18140903100,19140903100), Shanghai Municipal Health Commission (2020YJZX0213), Clinical Research Plan of Shanghai Hospital Development Center (SHDC2020CR1047B-003).

Competing interests None declared.

Patient consent for publication Not applicable.

Ethics approval This study was approved by the Ethics Committees of Xinhua Hosptial(XHEC-C2015-006) and WHO (A65899). Since only anonymous clinical information were collected, no individual informed consent was obtained.

Provenance and peer review Not commissioned; externally peer reviewed. Data availability statement № data are available.

Supplemental material This content has been supplied by the author(s). It has not been vetted by BMJ Publishing Group Limited (BMJ) and may not have been peer-reviewed. Any opinions or recommendations discussed are solely those of the author(s) and are not endorsed by BMJ. BMJ disclaims all liability and responsibility arising from any reliance placed on the content. Where the content includes any translated material, BMJ does not warrant the accuracy and reliability of the translations (including but not limited to local regulations, clinical guidelines, terminology, drug names and drug dosages), and is not responsible for any error and/or omissions arising from translation and adaptation or otherwise.
Open access This is an open access article distributed in accordance with the Creative Commons Attribution Non Commercial (CC BY-NC 4.0) license, which permits others to distribute, remix, adapt, build upon this work non-commercially, and license their derivative works on different terms, provided the original work is properly cited, appropriate credit is given, any changes made indicated, and the use is non-commercial. See: http://creativecommons.org/licenses/by-nc/4.0/.

\section{ORCID iD}

Jing Hua http://orcid.org/0000-0001-7613-0926

\section{REFERENCES}

1 Spong CY. Defining "term" pregnancy: recommendations from the defining "term" pregnancy workgroup. JAMA 2013;309:2445-6.

2 Mally PV, Agathis NT, Bailey SM. Early term infants are at increased risk of requiring neonatal intensive care. World J Pediatr 2016;12:76-81.

3 Craighead DV. Early term birth: understanding the health risks to infants. Nurs Womens Health 2012;16:136-45.

4 Reddy UM, Bettegowda VR, Dias T, et al. Term pregnancy: a period of heterogeneous risk for infant mortality. Obstet Gynecol 2011;117:1279-87.

5 Nielsen TM, Pedersen MV, Milidou I. Long-Term cognition and behavior in children born at early term gestation: a systematic review. Acta Obstet Gynecol Scand 2019;98:1227-34.

6 Chen C, Zhang JW, Xia HW, et al. Preterm birth in China between 2015 and 2016. Am J Public Health 2019;109:1597-604

7 Zou L, Wang X, Ruan Y, et al. Preterm birth and neonatal mortality in China in 2011. Int J Gynaecol Obstet 2014;127:243-7.

8 Xue Q, Shen F, Gao Y, et al. An analysis of the medical indications for preterm birth in an obstetrics and gynaecology teaching hospital in Shanghai, China. Midwifery 2016;35:17-21.

9 Zhang X, Zhou M, Chen L, et al. Risk factors for preterm birth: a case-control study in rural area of Western China. Int J Clin Exp Med 2015;8:4527-32.

$10 \mathrm{Lu}$ L, Qu Y, Tang J, et al. Risk factors associated with late preterm births in the underdeveloped region of China: a cohort study and systematic review. Taiwan J Obstet Gynecol 2015;54:647-53.

11 Liu L, Liu J-meng, Liu Y-hui, et al. [Prevalence of preterm birth among singletons in 10 counties (cities) of China, 1993-2005]. Zhonghua Liu Xing Bing Xue Za Zhi 2007;28:1051-4.

12 Newnham JP, Sahota DS, Zhang CY, et al. Preterm birth rates in Chinese women in China, Hong Kong and Australia - the price of Westernisation. Aust N Z J Obstet Gynaecol 2011:51:426-31.

13 Fan SL, Xiao CN, Zhang YK, et al. How does the two-child policy affect the sex ratio at birth in China? A cross-sectional study. BMC Public Health 2020;20:789.

14 Zhang $X$, Chen L, Wang $X$, et al. Changes in maternal age and prevalence of congenital anomalies during the enactment of China's universal two-child policy (2013-2017) in Zhejiang Province, China: an observational study. PLoS Med 2020;17:e1003047.

$15 \mathrm{Li} \mathrm{H}-\mathrm{T}$, Xue M, Hellerstein S, et al. Association of China's universal two child policy with changes in births and birth related health factors: national, descriptive comparative study. $B M J$ 2019;366:14680.

16 Teng X, Shane MI, Pan S. The changing situation about maternal age, risk factors and pregnancy outcomes after the two-child policy: a retrospective cohort study. Ann Palliat Med 2020;9:824-34.

17 Liu J, Song L, Qiu J, et al. Reducing maternal mortality in China in the era of the two-child policy. BMJ Glob Health 2020;5:e002157.

18 Jolly M, Sebire N, Harris J, et al. The risks associated with pregnancy in women aged 35 years or older. Hum Reprod 2000;15:2433-7.

19 Brown HK, Speechley KN, Macnab J, et al. Biological determinants of spontaneous late preterm and early term birth: a retrospective cohort study. BJOG 2015;122:491-9.

20 Feng XL, Wang Y, An L, et al. Cesarean section in the People's Republic of China: current perspectives. Int J Womens Health 2014;6:59-74.

21 Liu X, Landon MB, Cheng W, et al. Cesarean delivery on maternal Request in China: what are the risks and benefits? Am J Obstet Gynecol 2015;212:817 e1-9.

22 Kayem G, Raiffort C, Legardeur H. Specific particularities of uterine scars and their impact on the risk of uterine rupture in case of trial of labor]. J Gynecol Obstet Biol Reprod 2012;41:753-71.

23 Kiran TSU, Chui YK, Bethel J, et al. Is gestational age an independent variable affecting uterine scar rupture rates? Eur $J$ Obstet Gynecol Reprod Biol 2006;126:68-71.

24 Yan J, Wang L, Yang Y. The trend of caesarean birth rate changes in China after 'universal two-child policy' era: a population-based study in 2013-2018. BMC Med 2020;18:249. 
25 Shah A, Faundes A, Machoki M'Imunya, et al. Methodological considerations in implementing the who global survey for monitoring maternal and perinatal health. Bull World Health Organ 2008;86:126-31.

26 Souza JP, Gülmezoglu AM, Vogel J, et al. Moving beyond essential interventions for reduction of maternal mortality (the who multicountry survey on maternal and newborn health): a crosssectional study. Lancet 2013;381:1747-55.

27 Chen C, Zhang JW, Xia HW, et al. Preterm birth in China between 2015 and 2016. Am J Public Health 2019;109:1597-604.

28 Cooper S, Somerset D. Determination of gestational age by ultrasound. J Obstet Gynaecol Can 2016;38:337.

29 Bisahnyui P, Nkfusai CN, Bede F, et al. Comparative study of clinical methods versus ultrasound methods for accurate gestational age determination in different trimesters of pregnancy, Ndop district Hospital, North West region, Cameroon. Pan Afr Med J 2020;37:4.

30 Andersen HF, Johnson TR, Barclay ML, et al. Gestational age assessment. I. analysis of individual clinical observations. Am J Obstet Gynecol 1981;139:173-7.

31 Hittner HM, Gorman WA, Rudolph AJ. Examination of the anterior vascular capsule of the lens: II. assessment of gestational age in infants small for gestational age. J Pediatr Ophthalmol Strabismus 1981;18:52-4.

32 Laughon SK, Reddy UM, Sun L, et al. Precursors for late preterm birth in singleton gestations. Obstet Gynecol 2010;116:1047-55.

33 Krispin E. Management of premature rupture of membranes at term: the need to correct a recurring mistake in articles, chapters, and recommendations of professional organizations. Am J Obstet Gynecol 2017;217:661 e1-61.

34 Jiang H, Lu C, Zhou J, et al. Cesarean section and pregnancy outcomes of preterm premature rupture of membranes under different fertility policies in China. Trans/ Pediatr 2021;10:973-83.

35 Coulm B, Blondel B, Alexander S, et al. Elective induction of labour and maternal Request: a national population-based study. BJOG 2016;123:2191-7.

36 Entringer AP, Pinto M, Gomes MAdeSM. Cost-Effectiveness analysis of natural birth and elective C-section in supplemental health. Rev Saude Publica 2018;52:91.

37 Sharifzadeh F, Kashanian M, Jouhari S, et al. Relationship between pre-pregnancy maternal BMI with spontaneous preterm delivery and birth weight. J Obstet Gynaecol 2015;35:354-7.

38 Torloni MR, Betrán AP, Daher S, et al. Maternal BMI and preterm birth: a systematic review of the literature with meta-analysis. $J$ Matern Fetal Neonatal Med 2009;22:957-70.

39 WHO Expert Consultation. Appropriate body-mass index for Asian populations and its implications for policy and intervention strategies. Lancet 2004;363:157-63.

40 Zou G. A modified poisson regression approach to prospective studies with binary data. Am J Epidemiol 2004;159:702-6.

41 Cao Q, Wu Z, Sun Y, et al. [Application of negative binomial regression and modified Poisson regression in the research of risk factors for injury frequency]. Wei Sheng Yan Jiu 2011;40:702-4.

42 Richards JL, Kramer MS, Deb-Rinker P, et al. Temporal trends in late preterm and early term birth rates in 6 high-income countries in North
America and Europe and association with clinician-initiated obstetric interventions. JAMA 2016;316:410-9.

43 Barros JG, Clode N, Graça LM. Prevalence of late preterm and early term birth in Portugal. Acta Med Port 2016;29:249-53.

44 Barros FC, Rabello Neto DdeL, Villar J, et al. Caesarean sections and the prevalence of preterm and early-term births in Brazil: secondary analyses of national birth registration. BMJ Open 2018;8:e021538.

45 Carolan M, Davey M-A, Biro MA, et al. Older maternal age and intervention in labor: a population-based study comparing older and younger first-time mothers in Victoria, Australia. Birth 2011;38:24-9.

46 Carolan M, Frankowska D. Advanced maternal age and adverse perinatal outcome: a review of the evidence. Midwifery 2011;27:793-801.

47 Murta EFC, Nomelini RS. Is repeated caesarean section a consequence of elective caesarean section? Lancet 2004;364:649-50.

48 Mohammed A-BF, Bayo Al, Abu-Jubara MF. Timing of elective repeated cesarean delivery in patients with previous two or more cesarean section. J Matern Fetal Neonatal Med 2013;26:10-12.

49 Hutcheon JA, Joseph KS, Kinniburgh B, et al. Maternal, care provider, and institutional-level risk factors for early term elective repeat cesarean delivery: a population-based cohort study. Matern Child Health J 2014;18:22-8.

50 Little SE, Robinson JN, Puopolo KM, et al. The effect of obstetric practice change to reduce early term delivery on perinatal outcome. $J$ Perinatol 2014;34:176-80.

51 Osterman MJ, Martin JA. Recent declines in induction of labor by gestational age. NCHS Data Brief 2014;155:1-8.

52 Trembath AN, lams JD, Walsh M. Quality initiatives related to moderately preterm, late preterm, and early term births. Clin Perinatol 2013;40:777-89.

53 Oshiro BT, Kowalewski L, Sappenfield W, et al. A multistate quality improvement program to decrease elective deliveries before 39 weeks of gestation. Obstet Gynecol 2013;121:1025-31.

54 Berrien K, Devente J, French A, et al. The perinatal quality collaborative of North Carolina's 39 weeks project: a quality improvement program to decrease elective deliveries before 39 weeks of gestation. N C Med J 2014;75:169-76.

55 Lu L, Duan Z, Wang Y, et al. Mental health outcomes among Chinese prenatal and postpartum women after the implementation of universal two-child policy. J Affect Disord 2020;264:187-92.

56 Fretts RC, Schmittdiel J, McLean FH, et al. Increased maternal age and the risk of fetal death. N Engl J Med 1995;333:953-7.

57 Hung TH. Advanced maternal age and adverse perinatal outcome: a call for investigations on Asian women. Taiwan J Obstet Gynecol 2008;47:257-8.

58 Jacobsson B, Ladfors L, Milsom I. Advanced maternal age and adverse perinatal outcome. Obstetrics \& Gynecology 2004:104:727-33.

59 Zhao J, Shan N, Yang X, et al. Effect of second child intent on delivery mode after Chinese two child policy implementation: a cross sectional and prospective observational study of nulliparous women in Chongqing. BMJ Open 2017;7:e018823. 